\title{
EPIDERMAL GROWTH FACTOR, BUT NOT CORTISOL, SUPPRESSES FIBRE GROWTH IN CULTURED FOLLICLES
}

\author{
H. R. Ansari-Renani' and P. I. Hynd ${ }^{2}$ \\ I- Animal Science Research Institute, P.O. Box 31585-1483, Karaj, Iran, 2-Department of Animal \\ Sciences, University of Adelaide, Waite Campus, Glen Osmond, S. A. 5064
}

\section{SUMMARY}

This experiment was conducted to examine the role of cortisol and epidermal growth factor (EGF) in the growth of cultured follicles. Intact Tukidale and Romney anagen hair follicles $(n=12 /$ dose) were isolated from skin strips and maintained in Williams E medium supplemented with $1 \mathrm{mM}$ L-glutamine, Fungizone and antibiotics. Measurement of the changes in length of the follicles was made using an image analysis system. Tukidale and Romney follicles were incubated in medium containing $0,10,50$ and $1000 \mathrm{ng} / \mathrm{ml}$ of cortisol for a period of 3 days. The averages of growth rate of Tukidale primary and secondary and Romney follicles were 406 (range 146-764), $173(108-307)$ and 255 (81-546) $\mu \mathrm{m} /$ day, respectively. The pattern of [methyl- ${ }^{3} \mathrm{H}$ ]thymidine uptake showed that typical pattern of DNA synthesis is taking place in culture follicles.

Physiological and supra-physiological concentrations of $0,10,50$ and $1000 \mathrm{ng} / \mathrm{ml}$ of cortisol had no effect on the growth of Tukidale primary and secondary follicles over a $3 \mathrm{~d}$ period. Similarly, at the same concentrations cortisol had no effect on fibre growth from Romney follicles. Tukidale primary follicles with dermis and without dermis maintained with cortisol at 0 and $50 \mathrm{ng} / \mathrm{ml}(\mathrm{n}=12 /$ dose/treatment $)$ over a period of $6 \mathrm{~d}$ had no effect on follicle growth. EGF concentrations at $0.125,0.25,0.5,1,25$ and $50 \mathrm{ng} / \mathrm{ml}$ significantly $(\mathrm{P}<0.05)$ reduced fibre growth of primary and secondary follicles. Observations made on follicles maintained with EGF revealed that morphological changes were noticeable in the follicle bulb around the dermal papilla. The fibres of cultured follicles were firmly attached to inner root sheath forming a üistorted fibre end.

Keywords: Tukidale, Romney, follicle, culture, medium, cortisol, EGF

\section{INTRODUCTION}

The hormonal basis of follicle shutdown and fibre shedding has not yet been fully elucidated. High levels of follicle shutdown and fibre shedding leading to formation of wool breaks have been induced in Merino sheep injected with cortisol (Chapman and Bassett, 1970), suggesting that high plasma cortisol concentration may be involved in the tender wool problem, but there is mounting evidence (Moore et al., 1982; Singh-Asa and Waters, 1983; Chapman and Hardy, 1988; Philpot et al., 1990; and Behrendt et al., 1993) which suggest that other factors may also be involved in this process.

Epidermal growth factor, developed as a defleecing agent, would be a potential physiological candidate in the formation of wool breaks. Sheep injected with low doses of EGF, shed fibres and bore a zone of weakness or wool breaks (Moore et al., 1981). When human hair follicles were maintained with EGF in vitro at a concentration of $10 \mathrm{ng} / \mathrm{ml}$, there was a striking change in the morphology of follicles (Philpot $e t$ al., 1990) but the effect of low concentrations of EGF is unknown.

It has been indicated that intravenous infusion of defleecing doses of EGF caused a seven fold increase in plasma cortisol concentration (Singh-Asa and Waters, 1983), which is sufficient to induce follicle shutdown and initiate wool breaks. Localization of receptors for EGF in the wool follicle of Merino sheep (Wynn et al., 1989) and the finding that ACTH immunization increases the efficacy of EGF (Behrendt $e t$ al., 1993; Adam and Wynn, unpublished) suggest that there may be a possible association between these two depilatory substances. The key objectives of this study are to examine the role of cortisol and EGF in follicle shutdown and to investigate the effect of different concentrations of EGF and cortisol on primary and secondary wool follicles.

To achieve these objectives, it is necessary to study the action of EGF and cortisol at the follicular level. This, together with the fact that concentrations at the level of wool follicles in vivo, are unknown, points to 
the need for and investigations of the response of wool follicles in vitro. Studies in vitro have the advantage of allowing direct effects of substances on follicle function to be determined. An in vitro technique which involved microdissection of anagen follicles from human scalp skin has been reported by Philpott et al. (1990). More recently, Hynd et al. (1992) have modified this technique using fine needles to isolate follicles from skin strips and successfully maintained Romney wool follicles in Williams E medium.

\section{MATERIALS AND METHODS}

Williams E Medium was obtained from Gibco Laboratories (New York, New York), Phosphate buffered saline (PBS) from Sigma Diagnostics (St. Louis, Missouri) and [methyl $\left.-^{3} \mathrm{H}\right]$ thymidine was obtained from Amersham Australia (North Ryde, NSW). Trichloroacetic acid (TCA) and glycerol (AnalR) were products from BDH chemical (Kilsyth, Vic). The tissue culture wells (3424 Mark II) were products from Apex Laboratories (St. Marys, NSW), $1 \mathrm{mM}$ L-glutamine from Sigma Diagnostics (St. Louis, Missouri), Fungizone $(2.5 \mu \mathrm{g} / \mathrm{ml})$ and Penicillin/Streptomycin (100 units/ml) from Gibco Laboratories (New York, New York).

Photographic gel (L-4 Emulsion in Gel form) was obtained from Ilford Scientific Products (Mobberley, Cheshire) and the fixer (Hypam X-Ray Rapid Fixer), Hardner (Hypam X-Ray Hardner) and developer (Phenisol X-Ray Developer) were all products from Ilford (Mt. Waverley, Vic).

\section{Follicle isolation and length measurement}

Wool follicles were isolated from skin strips $(0.5 \mathrm{~mm} \times 1.0 \mathrm{~cm})$ taken from the locally-anaesthetised (Lignocaine hydrochloride) mid-side of adult sheep. Intact anagen hair follicles were gently removed from the collected skin strips using fine needles and cut at the sebaceous gland level. Isolated hair follicles were maintained in $500 \mu \mathrm{l}$ of Williams E medium supplemented with $1 \mathrm{mM} \mathrm{L}$-glutamine, Fungizone $(2.5 \mu \mathrm{g} / \mathrm{ml})$ and penicillin/streptomycin (100 units $/ \mathrm{ml})$. Follicles were maintained in individual wells of 24-well plates at $37^{\circ} \mathrm{C}$ in an atmosphere of $5 \% \mathrm{CO}_{2} / 95 \%$ air. Measurement of the changes in length of the follicles was made at $144 x$ magnification using an image analysis system (Bioquant IV, $R \&$ M Biometrics, USA). The distance from the base of the follicle bulb to the tip of the fibre was measured at $24 \mathrm{~h}$ intervals.

\section{DNA synthesis in the cultured follicles}

Follicles were grown in Williams E medium plus additives for 72 hours, then incubated in $3.7 \times 10^{4} \mathrm{~Bq}$ $(1 \mu \mathrm{Ci})$ of [methyl- ${ }^{3} \mathrm{H}$ ] thymidine (specific activity $0.67 \mathrm{mCi} \mu$ mole) for 6 hours. After incubations were completed, individual follicles were washed four times in $5 \%$ trichloroacetic acid (TCA). Follicles were then placed in millipore filters and set in micropore cassettes. Follicles were dehydrated through a series of graded ethanols and sectioned at $8 \mu \mathrm{m}$ thickness. In the darkroom under Ilford Safelight F904 all deparaffinised sections were immersed into $2 \%$ glycerol solution and drained.

The box of slides was wrapped in a light-proof box and kept at $4^{\circ} \mathrm{C}$ in the refrigerator for at least 7-8 weeks before developing. In the dark room slides were removed from the box and placed into a coplin jar containing kodak D19 developer (undiluted) for 2.5 minutes, distilled water for 10-20 seconds and katafix liquid fixer (diluted 1:4) containing llford Hardner (diluted 1:40) for 2 minutes. Sections were stained with a special tetrachrome stain "Sacpic" (Auber, 1952) to demonstrate follicular tissue component.

\section{Addition of cortisol and EGF to cultured follicles}

Tissue culture tested cortisol and EGF (Sigma Diagnostics, St. Louis, Missouri) were reconstituted in a solution of $1.0 \%$ bovine serum albumin (BSA) in phosphate buffered saline (PBS) obtained from Sigma Diagnostics (St. Louis, Missouri). Tukidale (primary and secondary) and Romney follicles $(n=12 /$ dose) were incubated in medium containing $0,10,50$ and $1000 \mathrm{ng} / \mathrm{ml}$ of cortisol for a period of 3 days. Fibre growth in Tukidale primary follicles with dermis was compared with the fibre growth of Tukidale primary follicles without dermis, maintained with cortisol at 0 and $50 \mathrm{ng} / \mathrm{ml}(\mathrm{n}=12 /$ dose/treatment) over a period of 6 days.

To examine the effect of different doses of EGF on Tukidale (primary and secondary follicle types) and Romney follicle growth in vitro, comparison was made between controlled follicles $(\mathrm{n}=12)$ and follicles $(\mathrm{n}$ $=12 /$ dose) maintained with $0.125,0.25,0.5,1,25$ and $50 \mathrm{ng}$ of EGF $/ \mathrm{ml}$. 


\section{Statistical analysis}

Growth rate was estimated as the slope of regression line relating fibre length to time. The slope of the regression was estimated with the Cricket graph computer software package (Version 1.3.1; Cricket Software, Philadelphia, U.S.A.). This was used to determine the average growth rate of follicles over a 3 day period and to compare the results obtained from different treatments.

Analysis of variance was performed using the Super ANOVA computer package (1989-1990, Abacus Concepts, Inc. Berkeley, California). Duncan's new multiple range test was then used to compare the follicle groups. The effect of EGF dose and follicle type on fibre growth was also determined.

\section{RESULTS}

Preliminary studies on the growth of follicles in culture

Fibre length significantly $(\mathrm{P}<0.05)$ increased in vitro with time (Figure 1). The average growth rate of Tukidale primary and secondary and Romney follicles cultured in Williams E medium was 406 (range 146764), 173 (108-307) and 255 (81-546) $\mu \mathrm{m} /$ day, respectively. Photographs of cultured follicles revealed that the length growth was due to normal growth of fibre. In addition, the pattern of [methyl ${ }^{3} \mathrm{H}$ ] thymidine uptake by cultured follicles showed that the typical pattern of DNA synthesis is taking place, an indication of normal mitosis. Autoradiography observations revealed that the majority of cell division takes place in the bulb cells around the dermal papilla.

The effect of cortisol on the growth of follicles in culture

Physiological and supra-physiological concentrations of cortisol had no effect on the growth of Tukidale primary and secondary follicles over a 3 day period (Table 1). Similarly at the same concentrations, cortisol had no effect on fibre growth from Romney follicles (Table 2).

Table 1. Effect of cortisol on the growth of Tukidale primary and secondary follicles in vitro

\begin{tabular}{ccc}
\hline $\begin{array}{c}\text { Cortisol concentration } \\
\mathrm{ng} / \mathrm{ml}\end{array}$ & \multicolumn{2}{c}{ Follicle length $(\mu \mathrm{m})$} \\
\hline 0 & $377^{\mathrm{a}} \pm 140$ & Secondary \\
\hline 10 & $379^{\mathrm{a}} \pm 134$ & $34^{\mathrm{b}} \pm 11.8$ \\
50 & $420^{\mathrm{a}} \pm 146$ & $38^{\mathrm{b}} \pm 12.6$ \\
1000 & $411^{\mathrm{a}} \pm 150$ & $61^{\mathrm{b}} \pm 21.4$ \\
\hline
\end{tabular}

${ }^{a b}$ Different superscripts differ in follicle growth at $P<0.05$.

Table 2. Effect of cortisol on the growth of Romney follicles in vitro

\begin{tabular}{cc}
\hline Cortisol concentration, $\mathbf{n g} / \mathbf{m l}$ & Follicle length, $(\mu \mathrm{m})$ \\
\hline 0 & $131 \pm 17$ \\
10 & $135 \pm 19$ \\
50 & $100 \pm 19$ \\
100 & $121 \pm 13$ \\
\hline
\end{tabular}

Different concentrations of cortisol had no effect on the growth of Tukidale primary follicles with or without dermis over a 6 days period (Table 3). No morphological changes were observed in cortisol treated cultured follicles. 


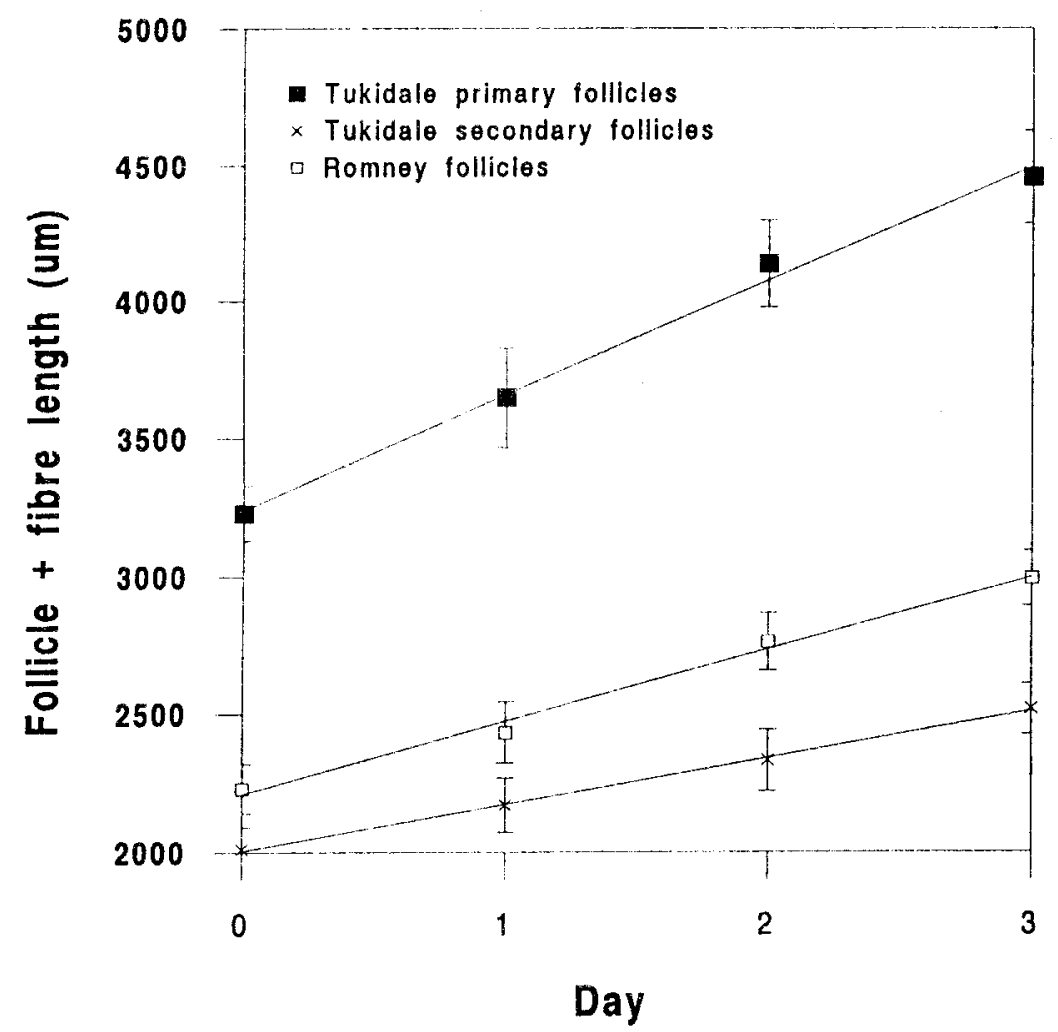

Figure 1. Romney and Tukidale follicles grow in a linear fashion for 3 days in culture. Results are expressed as the means with s.e.m. for increase in length $(\mu \mathrm{m})$ of follicles plus fibre $(n=12)$ isolated from skin strip.

The effect of EGF on the growth of follicles in culture

All concentrations of EGF $(\geq 0.125 \mathrm{ng} / \mathrm{ml})$ significantly $(\mathrm{P}<0.05)$ reduced the fibre growth of Romney wool follicles (Table 4). Since primary and secondary follicles responded differently to cortisol injection in vivo (unpublished) and no study has yet been done with EGF in this respect, the effect of different concentrations of EGF on the fibre growth of Tukidale primary and secondary follicles was studied. EGF at concentrations of 1,10 and $50 \mathrm{ng} / \mathrm{ml}$ significantly $(P<0.05)$ reduced fibre growth of primary and secondary follicles (Table 5).

Table 3. Effect of cortisol on the growth of Tukidale primary follicles with and without dermis in vitro

\begin{tabular}{ccc}
\hline Cortisol concentration (ng) & $\begin{array}{c}\text { Follicle length }(\mu \mathbf{m}) \\
\text { With dermis }\end{array}$ & Without dermis \\
\hline 0 & $303 \pm 38$ & $301 \pm 32$ \\
50 & $308 \pm 29$ & $289 \pm 45$ \\
\hline
\end{tabular}


Table 4. Effect of EGF on the growth of isolated Romney wool follicles in vitro

\begin{tabular}{cc}
\hline EGF Concentration (ng) & Follicle length $(\mu \mathrm{m})$ \\
\hline 0 & $205^{\mathrm{c}} \pm 30$ \\
0.125 & $63^{\mathrm{a}} \pm 12.5$ \\
0.25 & $126^{\mathrm{b}} \pm 21$ \\
0.5 & $114^{\mathrm{b}} \pm 26$ \\
1 & $77^{\mathrm{ab}} \pm 21$ \\
25 & $82^{\mathrm{ab}} \pm 15$ \\
50 & $82^{\mathrm{ab}} \pm 11$ \\
\hline
\end{tabular}

${ }^{a b c}$ Different superscripts significantly differ at $\mathrm{P}<0.05$.

Table 5. Effect of EGF on the growth of isolated primary and secondary wool follicles in vitro

\begin{tabular}{ccc}
\hline EGF concentration $(\mathbf{n g} / \mathrm{ml})$ & \multicolumn{2}{c}{ Follicle length $(\mu \mathrm{m})$} \\
& Primary & Secondary \\
\hline 0 & $398^{\mathrm{d}} \pm 40$ & $177^{\mathrm{c}} \pm 26$ \\
1 & $189^{\mathrm{c}} \pm 18$ & $73^{\mathrm{ab}} \pm 14$ \\
50 & $107^{\mathrm{ab}} \pm 18$ & $63^{\mathrm{ab}} \pm 20$ \\
& $130^{\mathrm{bc}} \pm 35$ & $45^{\mathrm{a}} \pm 8$ \\
\hline
\end{tabular}

abcd Different superscripts differ significantly at $P<0.05$.

Analysis of variance revealed that there was no significant interaction between follicle type and EGF dose, indicating that follicle types had similar susceptibility to EGF in vitro.

The morphology of wool follicles maintained with EGF $\geq 0.125 \mathrm{ng} / \mathrm{ml}$ was substantially changed with a subsequent cessation of fibre production. Observations made on follicles maintained with EGF over a 72 hour period revealed that changes were particularly noticeable in the follicle bulb around the dermal papilla. The fibres of cultured follicles were firmly attached to the inner root sheath forming a distorted fibre end and this structure extruded from the follicle bulb.

\section{DISCUSSION}

\section{Preliminary studies on the growth of follicles in culture}

As previously shown (Hynd et al., 1992) wool and hair follicles can be successfully maintained in vitro. Growth was linear for at least 3 days, and approached $50 \%$ of "in vivo" rates. The average fibre length growth of Tukidale primary and secondary and Romney follicles cultured in Williams E medium over a 3 day period was 406 (range 146-764) and 173 (range 108-307) and $140(85-270) \mu \mathrm{m} /$ day respectively, which is at about half the average in vivo rate (Woods and Orwin, 1988). Considerable variation in fibre length growth was observed between follicles. Depletion or absence of a particular growth factor or essential nutrients could be a possible reason for this variation.

Considerable variation was also found in the average fibre length growth of control Tukidale primary and secondary and Romney follicles maintained in culture over a 3 day period in different experiments in a range of 303-406, 139-173 and 103-255 $\mu \mathrm{m} /$ day respectively. Since in vitro experiments were conducted in different seasons using different adult sheep, the variation in fibre length growth could be due to seasonal and between sheep differences in fibre production. Seasonal variation in wool growth in sheep is a well established phenomenon (Coop and Hart, 1953; Ryder, 1956; Hutchinson and Wodzicka-Tomaszewska, 1961; Slee and Carter, 1961) with the greatest length of wool grown in summer and early autumn (Hardy, 1950). 
Photographs taken for growing follicles in vitro indicated that the growth of follicles were associated with the growth of both follicle inner root sheath and fibre. Furthermore the pattern of cell division and DNA-synthesis in cultured follicles was investigated by incorporating [methyl-3 ${ }_{\mathrm{H}}$ ] thymidine into culture medium. The results of [methyl-3 ${ }_{\mathrm{H}}$ ] thymidine autoradiography demonstrated a typical pattern of DNAsynthesis is taking place in the freshly isolated follicle. Even though the observation that the majority of cell division takes place in the follicle bulb around the dermal papilla suggest that follicle culture is a valuable system for the understanding of follicle activity, however further investigation is needed to improve the system in order to decrease high variation in fibre growth of follicles.

\section{The effect of cortisol hormone on the growth of follicles in culture}

The results of in vitro experiments indicated that addition of different concentrations of cortisol in the medium had no significant inhibitory effect on fibre growth over a 3 days period. Wallace (1979) also stated that unpublished results of Ward suggest that cortisol has no effect on wool follicles under conditions imposed on in vitro cultures of wool follicles within 6 hours. Culture of skin slices taken from an adrenalectomised sheep and placed in media containing cortisol at concentrations of physiological level had little effect on $\left[3_{H}\right]$ thymidine uptake (Hynd and Applebee, unpublished). In another study, Scobie (1992) showed that over the range of doses used, 4-6 hours after exposure, cortisol had little effect on the functioning of wool follicles in vitro. While these studies indicate that cortisol does not suppress cell division in the short term, longer periods of exposure of cultured follicles to cortisol have not yet been studied. To examine whether a ionger period of exposure to cortisol would inhibit fibre growth, follicles were maintained with supraphysiological concentrations of cortisol for 6 days. The results indicated that the growth rate of follicles maintained with cortisol was not affected. The possibility that some locallyproduced inhibitory factor associated with dermis (Moore, 1989) may inhibit the action of cortisol in vitro, was examined by removing dermis from dissected follicles. The results indicated that there was no significant difference in fibre growth with or without dermis, maintained with supraphysiological concentrations of cortisol for a period of 6 days. Furthermore, the morphology of follicles was not affected with addition of different concentrations of cortisol to the medium.

\section{The effect of EGF on the growth of follicles in culture}

If cortisol response is effected through another factor, a review of literature revealed that a potential depilatory substance which has a close association with cortisol was EGF. Singh-Asa and Waters (1983) indicated that infusion of defleecing doses of EGF caused a seven fold increase in plasma cortisol concentration, which is sufficient to inhibit fibre production and initiate wool breaks. Sheep injected with EGF shed some fibres and had a zone of weakness or wool breaks (Hollis et al., 1983). The appearance of wool breaks in EGF treated sheep resembled that of the break in sheep treated with cortisol and ACTH (Lindner and Ferguson, 1956). The imposition of psychosocial stress and the ACTH immunisation increased the efficacy of EGF as a wool harvesting agent, resulting in $60 \%$ weaker staples than the unstressed non-immunised sheep (Behrendt et al., 1993; Behrendt, 1994). The study of Adams and Wynn showed that cortisol administration actually suppressed EGF receptor numbers without altering receptor affinity. However in this study EGF defleecing was not attempted. These studies and the localization of receptors for EGF in the skin of sheep (Wynn et al., 1989) suggest that a strong association exists between EGF and cortisol in inhibiting wool production.

The present in vitro study is the first to show that very low concentrations of EGF inhibit fibre growth. All concentrations of EGF $\geq 0.125 \mathrm{ng} / \mathrm{ml}$ significantly $(P<0.05)$ inhibited fibre growth. EGF inhibition of fibre growth in vitro at concentrations of $\geq 0.125 \mathrm{ng} / \mathrm{ml}$ compares favourably with in vivo concentrations. Moore et al. (1982) demonstrated that intravenous infusion of Merino sheep with 3 to $5 \mathrm{mg}$ of EGF in many cases resulted in shedding of the entire fleece, but at lower doses of 1 to $3 \mathrm{mg}$, the fibres were found to have a zone of weakness.

Inhibition of fibre growth of EGF treated culture follicles is probably due to absence of elongation of fibre cells which normally commences in the suprabulbar region of anagen follicles (Hollis et al., 1983). This may come about by reduced cell proliferation in the follicle bulb and impaired protein synthesis in the fibre cells (Chapman, 1989) or from an increase in apoptosis (Kerr et al., 1972).

In all concentrations of EGF $\geq 0.125 \mathrm{ng} / \mathrm{ml}$, individual follicles were induced into a premature anagento-telogen transformation. Philpot et al. (1990) indicated that when follicles were maintained with EGF at a concentration of $10 \mathrm{ng} / \mathrm{ml}$, there was a striking change in the morphology of the human hair follicle, but 
they did not attempt to determine the effects of EGF on follicles at lower concentrations. The in vitro EGF action of follicle shutdown mimics the in vivo action of cortisol and EGF (Hollis et al., 1983). When sheep are injected with EGF over a period of 24 hours, delayed hardening of the layers of the inner root sheath is detectable within 6 hours of the start of the infusion and lasts for more than 48 hours (Hollis et al., 1983). This is accompanied by further disruption of the activity of the inner root sheath cells and the adjacent fibre in the upper part of keratogenous zone. Similarly in vitro cessation of fibre growth by EGF was accompanied by the characteristics of follicle shutdown. The earliest changes were detectable within hours of the addition of EGF. During this period, normal activity of follicles was observed to be disrupted in the keratogenous zone, where inner root sheath cells joined with fibre and formed a distorted end structure. Formation of distorted end structure was not accompanied by the characteristics of follicle shutdown where the distorted end fibre regress towards the skin surface, but rather this structure collapsed and extruded from the follicle bulb. The extrusion of distorted end fibre is probably due to delayed hardening and disruption of inner root sheath cells with both intra- and inter-cellular accumulation of fluid and flocculent material in the follicle (Chapman, 1989).

Statistical analysis revealed that there was no significant interaction between follicle types and EGF dose, indicating that primary and secondary follicles had a similar decrease in fibre growth. Since EGF is a potent depilatory substance, it is not unexpected to observe that follicle types respond similarly to this compound. Hollis et al. (1983) indicated that fibre and inner root sheath of sheep injected with $4.5-4.7 \mathrm{mg}$ of EGF were partially disrupted within the first 6 hours of infusion and all follicles stopped producing fibre within 6-8 days, suggesting that all follicles had similar degree of susceptibility to EGF.

\section{REFERENCES}

Auber, L., 1952. The anatomy of follicles producing wool-fibres, with special reference to keratinization. Transcripts of the Royal Society of Edinburgh, 62: 191-254.

Behrendt, R., 1994. The influence of stress on wool production and the occurrence of wool break/tenderness in Merino sheep. Proceedings of Australian Animal Production., 20: 70-71.

Behrendt, R., M. Luvio, R. D. G. Rigby, R. M. Hoskinson and P. C. Wynn., 1993. Both immunization against ACTH and chronic stress increase the efficacy of EGF as a wool harvesting agent. Proceedings of Endocrine Society of Australia., 36: 117.

Chapman, R. E., 1989. Follicular malfunctions and resultant effects on wool fibres. In; The Biology of Wool and Hair. pp243-257. Editors, G. E. Rogers, P. J. Reis, K.A. Ward and R.C. Marshall. Chapman and Hall, London.

Chapman, R. E. and J. M. Bassett., 1970. The effects of prolonged administration of cortisol on the skin of sheep on different planes of nutrition. Journal of Endocrinology., 48: 649-663.

Chapman, R. E. and Hardy, M. H., 1988. Effect of intradermally injected and topically applied mouse epidermal growth factor on wool growth, skin and wool follicles of Merino sheep. Australian Journal of Biological Science., 41: 261-268.

Coop, I. E. and D. S. Hart., 1953. Environmental factors affecting wool growth. Proceedings of New Zealand Society of Animal Production., 13: 113-119.

Hardy, J. I., 1950. Wool growth: Effect on environment and other factors. Textile research journal., 20: 189-193.

Hollis, D. E., R. E. Chapman, B. A. Panaretto, and G. M. Moore., 1983. Morphological changes in the skin and wool fibres of Merino sheep infused with mouse epidermal growth factor. Australian Journal of Bilogical Sciences. 36: 419-434.

Hutchinson, J. C. D. and M. Wodzicka-Tomaszewska., 1961. Climate physiology in sheep. Ainaml Breeding Abstract., 29: 14.

Hynd, P.I., L.M. Winder, and R. Brickerstaffe., 1992. Preliminary investigations of Romney wool growth in vitro. Wool Technology and Sheep Breeding., 40: 102- 105.

Kerr, J. F. R., A. H. Wyllie, and A. R. Currie., 1972. Apoptosis: a basic biological phenomenon with wideranging implications in tissue kinetics. British Journal of Cancer., 26: 239-257.

Lindner, H. R. and K. A. Ferguson., 1956 Influence of the adrenal cortex on wool growth and its relation to "break" and "tenderness" of the fleece. Naute, London., 177: 188-189. 
Moore, G. P. M., 1989. Growth factors, cell-cell and cell-matrix interactions in skin during follicle development and growth. In: The Biology of Wool and Hair. pp351-364. Editors, G. E. Rogers, P. J. Reis, K. A. Ward and R. C. Marshall. Chapman and Hall, London, New York.

Moore, G. P. M., B. A. Panaretto, and D. Robertson., 1981. Epidermal growth factor causes shedding of the fleece of Merino sheep. Search, Sydney., 12: 128-129.

Moore, G. P. M., B. A. Panaretto, and D. Robertson., 1982. Inhibition of wool growth in Merino sheep following administration of mouse epidermal growth factor and a derivative. Australian Journal of Biological Sciences., 35: 163-172.

Philpot, M. P., M. R. Green, and T. Kealey., 1990. Human hair growth in vitro. Jouranl of Cell Science., 97: 463-471.

Ryder, M. L., 1956. Observations of nutritional and seasonal changes in the fleeces of some Masham sheep. Journal of Agricultural Science, Cambridge., 47: 129-144.

Scobie, D. R., 1992. The short term effects of stress hormones on cell division rate in wool follicles. Ph. D. Thesis, University of Adelaide.

Singh-Asa, P. And M. J. Waters., 1983. Stimulation of adrenal biosynthesis by epidermal growth factor. Molecular and cellular endocrinology., 30: 189-199.

Slee, J. and H. B. Carter., 1961. A comparative study of fleece growth in Tasmanian Finewool and Wiltshire Horn ewes. Journal of Agricultural Science, Cambridge., 57:11-19.

Wallace, A. L. C., 1979. The effect of hormones on wool growth. In: Physiology and Environmental Limitations to Wool Growth. pp257-268. Editors, J. L. Black and P. J. Reis. University of New England publishing unit, Armidale, Australia.

Woods, J. L. and D. F. G. Orwin., 1988. Seasonal variation in the dimensions of individual Romney wool fibres determined by a rapid autoradiography technique. New Zealand Journal of Agriculture Research., $31: 311-323$.

Wynn, P. C., I. G. Maddock, G. P. M. Moore, B. A. Panaretto, P. Djura, W. G. Ward, E. Fleck, and R. E. Chapman., 1989. Characterization and localization of receptors for epidermal growth factor in ovine skin. Journal of Endocrinology, 121:81-90. 